\title{
ENVOLVIMENTO EMOCIONAL NO RELACIONAMENTO ENFERMEIRA-PACIENTE
}

\author{
Marilena de Freitas*
}

FREITAS, M. Envolvimento emocional no relacionamento enfermeira-paciente. Rev. Esc. Enf. USP, São Paulo, 18(1):85-89, 1984.

Este artigo dá ênfase à importância do envolvimento emocional no relacionamento terapêutico enfermeira-paciente, e descreve como esta experiência foi vivenciada num relacionamento de ajuda com um paciente internado em Hospital Psiquiátrico.

Existe certa dificuldade para o aluno aceitar o envolvimento emocional como aspecto importante no relacionamento enfermeira-paciente, devido ao que se aprende em disciplinas anteriores à de enfermagem psiquiátrica. Naquelas é dito que a enfermeira não deve se envolver com os problemas do paciente.

A importância desse envolvimento está no fato de que sem ele fica dificil desenvolver a aceitação e a empatia, essenciais para que a enfermeira possa realmente ser útil ao paciente.

Por outro lado, existe um aspecto importante a ser considerado. Esse envolvimento deve ficar em niveis terapêuticos. Para que isso ocorra, é necessário supervisão, direta e individual, no caso de alunas ou enfermeiras principiantes; ou, então, que a enfermeira discuta os acontecimentos e seus sentimentos com outro profissional, com mesmo nível de formação. Estas preocupações devem existir, pois um envolvimento emocional não terapêutico pode prejudicar o paciente.

Segundo STEFANELLI, ARANTES, FUKUDA (1982), para que o envolvimento emocional, no relacionamento enfermeira-paciente, seja realmente útil, é necessário que: o interesse da enfermeira esteja volta. do inteiramente para o paciente; os objetivos do relacionamento estejam claros para ambos; a enfermeira esteja consciente de seu papel terapêutico; a enfermeira utilize seus conhecimentos e habilidades em técnicas terapêuticas de comunicação; a enfermeira avalie constantemente sua atuação, considerando os sentimentos e a emoção que estão ocorrendo.

\footnotetext{
- Aluna do $8^{\circ}$ semestre do curso de Graduacão da Escola de Enfermagem da Universidade de São Paulo. Trabalho realizado na dísciplina Finfermagem Psiquiátrica 1 , no período do marco/abril de 1983.
} 
Feitas estas considerações teóricas, passarei a relatar minha experiência, que se deu em uma unidade psiquiátrica, durante o estágio da disciplina Enfermagem Psiquiátrica I.

Nosso estágio durou dois meses. Ficávamos no Hospital às segundas, quartas e sextas-feiras, no periodo da manhã. Nos três primeiros dias fizemos a observação de um paciente predeterminado; durante esses dias minha ansiedade aumentou muito. Conversei com a docente que me acompanhava sobre essa ansiedade e sobre a possibilidade de não desenvolver o relacionamento, pois, além de estar com medo dos pacientes, não acreditava que pudesse fazer alguma coisa por eles. Tinha atitude negativa em relação à disciplina e ao relacionamento terapêutico.

Fui informada, porém, de que isso não seria possível, pois o objetivo da disciplina era que aprendessemos a desenvolver relacionamento terapêutico com o paciente. Fiquei aborrecida, mas pela primeira vez pensei seriamente em desenvolver o mesmo.

Foi com essa atitude negativa, com medo e com ansiedade crescentes que comecei o relacionamento de ajuda com o paciente.

Durante os três primeiros dias fiz as observaçōes a seguir:

Paciente F.: tinha 27 anos e $174 \mathrm{~cm}$ de altura; estava aparentemente limpo e com vestuário adequado; seus cabelos eram loiros e despenteados e a barba estava por fazer; andava ligeiramente curvado para a frente. Permanecia a maior parte do plantão deitado em sua cama; levantava às vezes para acender um cigarro; enquanto fumava andava apressadamente pelo corredor; não participava das atividades recreativas da clínica, mesmo quando convidado; mantinha-se isolado; nada havia de particular com seu modo de falar; as idéias expressas eram coerentes; demorava para responder às perguntas e fazia pausas entre as frases. Parecia estar atento ao meio ambiente e às coisas que estavam ocorrendo. Durante as refeições apresentava maneiras adequadas à mesa; aceitava, geralmente, metade da porção de alimentos que lhe era oferecido.

Aparentemente tinha atitude negativa em relação a si próprio e às demais pessoas, pois não cuidava de sua aparência e não tomava iniciativa para interagir com as pessoas. Pelo contrário, mantinha-se afastado das demais pessoas. dados:

Com base nisto listei alguns comportamentos que deveriam ser mu-

- não cuidar de sua aparência pessoal;

- não participar das atividades recreativas da clínica;

- manter-se isolado;

- ingerir quantidade insuficiente de alimentos.

Na semana seguinte li o prontuário, conversei com o paciente. Teria que decidir se ficaria ou não com o paciente que havia observado para desenvolver o relacionamento de ajuda ou terapêutico. 
Os dados colhidos do prontuário foram os seguintes: tratava-se de um paciente com diagnóstico de Esquizofrenia Paranóide, sendo essa sua terceira internação neste Hospital. É o terceiro de uma prole de quatro filhos e tem uma irmã adotiva. Fez uso abusivo de drogas no periodo entre 17 e 19 anos. Trabalhou em vários locais. com a família. Veio ao Hospital acompanhado de sua mãe e não ofereceu resistência à internação. Após a internação foi tratado com um derivado butirofenônico.

Até o final dessa semana eu ainda não havia decidido se cuidaria deste paciente. No início, nos períodos que permanecia no Hospital, conversava com o paciente, mas sentia muita insegurança e medo. Ficava na unidade o mínimo de tempo possivel.

Com o passar do tempo, comecei a sentir-me melhor e já conseguia conversar com o paciente sem sentir tanto medo. Passei então a sentir necessidade de explicar-lhe quem eu era, o que estava fazendo no Hospital e qual o meu objetivo. Decidi então firmar meu compromisso de ajuda com o paciente e começar as entrevistas formais.

Foram realizadas 13 entrevistas formais e várias informais. No inicio, apesar de toda minha ansiedade, tentava ficar a maior parte do plantão a seu lado. Andávamos pelo corredor, convidava-o para jogar pingue-pongue; em geral ele não aceitava mas em um determinado dia ele chamou-me para jogar.

No final da primeira semana de entrevistas formais, após 10 dias de estágio, ele havia cortado os cabelos e feito a barba. Aceitava toda a alimentação oferecida e participava espontaneamente dos jogos realizados na unidade.

Durante as entrevistas ficava muito tensa e temia envolver-me emocionalmente com o paciente. Isto tornou-se para mim um problema pois realmente não queria me envolver.

Em uma entrevista com a docente, discutimos as medidas terapêuticas de relacionamento que estava usando, a fase do processo em que estávamos e ela frisou a necessidade do envolvimento emocional para evolução do processo de relacionamento terapêutico. Disse também que me avisaria quando o envolvimento estivesse ultrapassando o nivel terapêutico. Isto tranqüilizou-me.

Passei, então, a não ficar tão ansiosa durante as entrevistas e permiti que o envolvimento emocional ocorresse.

Isto repercutiu muito no comportamento do paciente. Ele passou a falar espontaneamente sobre sua vida, seus problemas e seus familiares. Gradualmente, o tempo de permanência dele ao meu lado foi aumentando, assim como aumentou a duração das entrevistas. Houve remissão da sintomatologia e ele passou a cuidar de sua aparência.

Paralelamente, meu interesse pelo paciente aumentava. Comecei a utilizar outras técnicas terapêuticas de comunicação. Não faltei mais ao estágio e aumentei meu número de horas de estudo. A ansiedade 
desapareceu, dando lugar a um interesse crescente pelo paciente e pelo campo da psiquiatria.

Encontrávamo-nos na segunda semana do relacionamento; neste período, seu médico estava planejando uma licença de fim-de-semana para breve. Tivemos uma semana de feriados, na qual não fomos ao Hospital. Preparei o paciente para esta semana.

A primeira entrevista após minha volta deixou claro que estávamos em plena fase de continuação do processo do relacionamento terapêutico. O paciente e eu estávamos analisando os elementos para elaborar alternativas de solução para seus problemas. Todos os fenômenos que predominantemente ocorrem nesta fase estavam evidentes; aceitação, dependência aceita, confiança, empatia, interdependência e envolvimento emocional.

As técnicas terapêuticas de comunicação que mais utilizei foram: saber ouvir; permanecer em silêncio; verbalizar aceitação; verbalizar interesse; repetir os comentários do paciente; repetir suas últimas palavras; devolver a pergunta feita; fazer perguntas relacionadas; colocar em foco a idéia principal e verbalizar dúvidas (STEFANELLI, 1983).

Tudo transcorria bem. Sentia-me à vontade na clínica e muito empolgada com o relacionamento e o estágio em si.

Oito dias após esta entrevista, ocorreu o que considerarei como incidente. Uma de minhas colegas de estágio, que estava na ala feminina, veio conhecer a unidade masculina. Apresentei-a ao paciente, ela inadivertidamente disse: "O Sr. é o Sr. F.? Ela (eu) fala muito no senhor. Fala bem é claro!". Aparentemente isso não o afetou. Porém, na entrevista seguinte notei que ele estava diferente. Falava pouco e quis terminar a entrevista antes do tempo previsto. A perda da confiança do paciente em minha pessoa, como profissional, tornou-se visivel nas entrevistas subseqüentes.

Os sintomas voltaram a se manifestar. Recomeçou a apresentar idéias delirantes e a testar-me. Isso deixou-me ansiosa, triste e deprimida. Estávamos quase ao final de estágio e deveria reconquistar sua confiança, básica para o processo terapêutico. Pensei em desistir mas o envolvimento era muito grande e impulsionava-me a continuar tentando.

Comecei, novamente, a falar sobre assuntos gerais, a caminhar a seu lado pelo corredor.

Quinze dias depois desse incidente, ele voltou a falar de si mesma e deixou de testar-me. Passou então a demonstrar uma certa preocupação com nossa separação, pois eu teria apenas mais duas semanas de estágio. Durante estas duas semanas discutimos seus problemas e planos para o futuro. Comecei a prepará-lo para o término do relacionamento. Na última semana de estágio promovemos (nós alunas) um torneio de tênis de mesa, na unidade, entre os pacientes. Meu paciente ganhou este torneio. Ficamos - eu e ele - muito felizes com isso. 
Devido ao incidente não houve oportunidade de promover maior independência do paciente, porém a assistência planejada para ele foi discutida com a enfermeira da unidade que se comprometeu a dar continuidade à mesma.

Fiquei muito triste com a separação e preocupada com o futuro do paciente. Voltei ao ambulatório do Hospital várias vezes para obter notícias suas através de seu médico, conforme havia sido combinado.

Quando o paciente recebeu alta hospitalar veio me procurar na Escola, acompanhado de sua mãe, para agradecer-me pela assistência recebida. Fiquei muito feliz com isso, e senti-me muito gratificada.

FREITAS, M. Emotional envolvement in the nurse-patient relationship. Rev. Esc. Enf. USP, São Paulo, 18(1):85-89, 1984.

This article gives emphasis to the importance of the emotional envolvement during the nurse-patient relationship in a Psychiatry Hospital. The author, a nursing student, describes her own fears and doubts and how, with the help of her instructors, she overcame them and was able to develop a therapeutic relationship.

\section{REFERENCIAS BIBLIOGRAFICAS}

STEFANELLI, M. C.; ARANTES, E. C.; FUKUDA, I. M. K. Aceitação, empatia e envolvimento emocional no relacionamento enfermeira-paciente. Rev. Esc. Wnif. USP, São Paulo, 16(3) :245-252, 1982.

\section{BIBLIOGRAFIA}

STEFANELLI, M. C.; ARANTES, E. C.; FUKUDA, I. M. K. Apoio como medida terapéutica no relacionamento enfermeira-paciente. Rev. Esc. Enf. USP, São Paulo, 15(1):43-48, 1981.

ORLANDO. I. J. O relacionamento dinâmico enfermeiro/paciente. São Paulo, E.P.U., EDUSP, 1978. 98 p. 